\section{Change the Equation: Improving science and mathematics education in the US}

\section{Change the Equation, a non-profit group of more than 100 corporate organizations, is committed to improving the state of mathematics and science education in the US.}

In 2009, the PISA (Programme for International Student Assessment) test, a standardized assessment developed and administered by the OECD (Organization for Economic Cooperation and Development) to 15 -year-olds in participating countries, revealed disappointing academic performances by US students. The results showed that US students lagged significantly behind their peers from participating countries in mathematics and science, with mathematics scores dropping to below average. Students in Shanghai, on the other hand, captured first place in all three categories tested - reading, mathematics and science. Other reports have also noted that an alarming proportion of US students seem to be inadequately prepared for college-level mathematics and science courses. Several indicators suggest that the US is falling behind other developed nations in standards of school education, and a failure to reverse this decline poses a threat to the long-term economic future of the country.

Spurred by the current crisis in education, President Obama launched the 'Educate to Innovate' campaign in 2009. This ambitious effort involving partnerships between private companies and non-profit organizations, including foundations and science and engineering societies, has the long-term goal of boosting the performance of US students in science, technology, engineering and mathematics (STEM).

In 2010, the corporate community responded to Obama's call for raising STEM literacy by forming Change the Equation (CTEq), a nonprofit coalition whose founders include the astronaut Sally Ride and the CEOs of many large corporations. The main aim of CTEq is to enhance STEM education for children, particularly girls and under-represented minorities, and to serve as a long-standing advocate for improved STEM literacy in the country. With this greater purpose in mind, CTEq has three key targets - to improve STEM teaching, to inspire enthusiasm in students for careers in STEM fields and to foster a broad commitment to science education from all sectors of society, including government, educators and business. As an alliance of over 100 companies representing diverse industries such as technology and telecommunications, biotechnology and pharmaceuticals, financial services and consultancy, and entertainment and publishing, CTEq has a combined purse of more than $\$ 500$ million a year of financial and in-kind support devoted to this effort.

In their first year, a key undertaking has been the development of metrics for evaluating the status of STEM education throughout the US; this 'scorecard' will serve as a basis for assessing future progress in STEM education. In April this year, CTEq released the 'Vital Signs' report on the condition of STEM education in each of the 50 states and in the District of Columbia. The results were compiled from publicly available data, including data from the National Assessment of Education Progress, and highlight several concerns that are widespread across the US. For example, the achievement gap between White students and their Black and Hispanic peers in mathematics and science is significant. There is also an urgent need to provide better training for elementary- and secondary-school mathematics teachers, and more challenging and engaging education in mathematics and science. The results also reveal that although some states have maintained high standards for students in mathematics and science, many others have dropped the bar, creating a false perception of student ability, and the report makes specific recommendations for improvement. In 2012, CTEq plans to issue a more detailed set of state-wide reports that will represent the most in-depth assessment of the status of STEM literacy to date and which will have the potential to become a crucial tool in evaluating and contrasting progress on a state-by-state basis.

Owing to the diverse companies in its network, many of which dominate their individual industries, CTEq has considerable resources, including financial and expert knowledge, within its reach. But the effectiveness of disparate engagement by varied companies is debatable. As part of their efforts to maximize fruitful corporate engagement in improving STEM education, CTEq has taken the important step of developing 'Design Principles for Effective STEM Philanthropy'. These principles serve not only as mechanism to broadly align the efforts of individual members but also to guide effective philanthropic engagement.

Nature Publishing Group's mission and strengths in science communication converge with the overall mission of CTEq. As a member of CTEq, Nature Publishing Group has developed the 'Bridge to Science' initiative, which includes six programmes supported by different divisions of Nature Publishing Group. Three programmes from Scientific American - Bring Science Home, 1000 Scientists in 1000 Days, and Citizen Science - are designed to inspire enthusiasm for science amongst parents and children, connect working scientists to teachers and engage the amateur scientist. Bring Science Home, for example, provides a series of quick, easy and fun science projects (making paper, talking through a string phone) to expose 6-12-year-olds to scientific concepts, whereas Citizen Science features diverse projects ranging from predictions of protein structure to understanding declining bee populations, and aims to draw in science hobbyists. The programmes supported by Nature Education, a division of Nature Publishing Group committed to facilitating global access to science education through innovative technology-driven tools, include Scitable, an open online learning and teaching portal aimed at undergraduates students and faculty in the life sciences, and Bench to Blackboard, a collaboration between Scitable and the Baylor College of Medicine to provide free, online course modules for middle- and highschool biology teachers. Finally, in a joint initiative with Cisco Systems, Nature Publishing Group will be developing a mechanism to assess the returns on national investment in STEM education by OECD countries.

The endeavours of CTEq follow in a long tradition of corporate philanthropy in the US and it should be commended for its commitment to tackling the pressing challenges in improving STEM literacy. But philanthropy alone will not suffice. Sustained long-term engagement from both the state and federal governments will be essential in the effort to address the crisis in US education. 